\title{
Injustiça testemunhal em Recordações do escrivão Isaías Caminha: um estudo sobre os efeitos dos vícios epistêmicos
}

\section{Testimonial injustice in Recordações do escrivão Isaías Caminha: a study on the effects of the epistemic vices}

José Renato Salatiel

https://orcid.org/0000-0001-5858-1248 - Email: jrsalatiel@hotmail.com

\begin{abstract}
RESUMO
Neste artigo argumentamos que a injustiça testemunhal, conforme teorizada por Fricker (2007), é uma categoria de vício epistêmico cujos efeitos prejudiciais são muito mais vastos e profundos sobre a vida intelectual. Para isso, analisamos casos de injustiça testemunhal causados por preconceito racial no romance Recordações do escrivão Isaías Caminha (1909), do escritor carioca Lima Barreto. O objetivo é mostrar como a injustiça testemunhal, entendida como um tipo de vício epistêmico, pode ter consequências negativas que afetam não somente os processos de inquirição, mas valores humanos. O presente artigo divide-se em duas seções. Na primeira classificamos a injustiça epistêmica como um tipo de vício epistêmico a partir da perspectiva de seus efeitos, com base nas obras de Fricker e Cassam (2019). A segunda seção é dedicada ao exame do referido romance de Lima Barreto, visando uma aplicação prática das teorias discutidas na seção anterior.
\end{abstract}

Palavras-chave: Injustiça testemunhal. Vícios epistêmicos. Preconceito racial. Epistemologia social. Lima Barreto.

\section{ABSTRACT}

In this paper we argue that testimonial injustice, as theorized by Fricker (2007), is a category of epistemic vices whose harmful effects on the intellectual life are far vast and deep than others. To achieve this, we analyze cases of testimonial injustice caused by racial prejudice in the novel 
Recordações do escrivão Isaías Caminha (1909), written by Brazilian author Lima Barreto. The objective is to show how testimonial injustice, understood as a kind of epistemic vice, has negative consequences which affect not only the process of inquiry but human values. This article is divided into two sections. In the first, we classify epistemic injustice as a type of epistemic vice, with regard to its effects, based on the works of Fricker and Cassam (2019). The second section is dedicated to an examination of the aforementioned novel of Lima Barreto, with the aim of providing a practical application of the theories discussed previously.

Keywords: Testimonial injustice. Epistemic vices. Racial prejudice. Social epistemology. Lima Barreto.

A capacidade mental dos negros é discutida a priori e a dos brancos, a posteriori

Lima Barreto. Diário Íntimo (1961, p. 61)

\section{Introdução}

A epistemologia dos vícios é um tema relativamente novo em Filosofia, com uma produção que remonta a pouco mais uma década. Da mesma forma, epistemologias sociais, que incluem estudos sobre epistemologia do testemunho e injustiças epistêmicas, são áreas de estudo recentes no campo da Epistemologia Analítica. Este artigo visa contribuir para o debate desses temas analisando o conceito de injustiça testemunhal, de Miranda Fricker (2007), como uma forma de vício epistêmico. Em particular, investigaremos os efeitos prejudiciais causados por condutas viciosas na inquirição.

A hipótese que sustentamos nesta pesquisa é a de que injustiças testemunhais são um tipo de vício epistêmico que gera efeitos muito mais abrangentes que outros vícios comumente elencados, como dogmatismo, covardia e arrogância intelectuais. Para demonstrar isso estudamos um tipo de injustiça testemunhal calcada em preconceitos raciais, e tomamos como estudo de caso a obra inaugural do escritor Lima Barreto, Recordações do escrivão Isaías Caminha (1909). Supomos que essa ficção possa fornecer exemplos práticos de injustiças epistêmicas.

$\mathrm{O}$ artigo divide-se em duas seções. Na primeira categorizamos a injustiça testemunhal como um vício epistêmico, com base nas teorias de Fricker (2007) e Quassim Cassam (2019). Detalhamos, em específico, os efeitos negativos dos vícios epistêmicos. Na segunda parte fazemos uma aplicação dessas teorias na interpretação de passagens extraídas do romance de Lima Barreto.

Concluímos que injustiças epistêmicas são uma das formas mais prejudiciais de vícios epistêmicos, pela qual agentes ou comunidades têm sua confiabilidade reduzida na produção de conhecimento em razão de preconceitos identitários. Argumentamos que elas não somente dificultam o pleno exercício de faculdades cognitivas, mas, considerando a vida intelectual um elemento intrínseco do valor humano, produz efeitos mais extensos e perduráveis.

\section{Injustiça testemunhal e vícios epistêmicos}

O testemunho é uma importante fonte de conhecimento que envolve um contrato de confiança, por meio do qual o ouvinte confere crédito ao falante, reconhecendo-o como agente 
epistêmico. O conhecimento testemunhal, assim, resulta de uma prática social e comunitária que, como qualquer outra, é perpassada por relações de poder (HADDOCK, MILLAR, PRITCHARD, 2010). A originalidade o trabalho de Miranda Fricker (2007) foi definir um tipo específico de marginalização social que incide sobre tais práticas epistêmicas. Nelas, os falantes são descreditados em função de preconceitos negativos por parte dos ouvintes, em particular, preconceitos racial e de gênero.

Fricker (2007) chamou essas relações de injustiças epistêmicas, que classificou em duas categorias distintas, mas relacionadas: testemunhal e hermenêutica. A primeira ocorre quando a credibilidade do falante é deflacionada, sistematicamente, por atitudes preconceituosas do ouvinte. Por exemplo, quando um veículo de imprensa prescinde da análise de um especialista negro, em uma reportagem, para ouvir um especialista branco com a mesma qualificação' ' Já a segunda, hermenêutica, diz respeito a experiências sociais que são impactadas de modo negativo por dispositivos sociais interpretativos. Um exemplo é o de mulheres que sofrem assédio sexual em um ambiente no qual, histórica e culturalmente, tal expressão ("assédio sexual") está ausente. $O$ foco deste artigo é a injustiça testemunhal.

O caso central de injustiça testemunhal, diz Fricker, é o preconceito identitário. Trata-se de um juízo depreciativo sobre determinados grupos sociais que resiste a evidências contrárias. Esse juízo é feito com base em estereótipos negativos que associam determinadas categorias sociais a esses grupos marginalizados (FRICKER, 2007, p. 35-36). O conceito é extensivo ao de preconceito racial, entendido como "[...] um juízo baseado em estereótipos acerca de indivíduos que pertençam a um determinado grupo racializado, e que pode ou não resultar em práticas discriminatórias" (ALMEIDA, 2020, p. 32).

Segundo Fricker, o preconceito identitário distorce a percepção que o ouvinte tem do falante, diminuindo sua (do falante) credibilidade. Esse mecanismo funcionaria, em grande parte, em níveis não-doxásticos, ou seja, sem que os ouvintes tenham consciência de que estão reproduzindo tais estereótipos (FRICKER, 2007, p. 36-37). São preconceitos implícitos e, amplamente, estruturais, no sentido de constituírem processos sociais que normatizam comportamentos individuais (ALMEIDA, 2020, p. 50).

A questão que nos interessa discutir aqui é: seria a injustiça testemunhal uma forma de vício epistêmico?

Vícios epistêmicos são modos de conduta ou traços de caráter, como arrogância, covardia, dogmatismo e preconceito, que impactam negativamente processos de aquisição e transmissão de conhecimento. Enquanto as virtudes epistêmicas (mente aberta, humildade, coragem, rigor intelectual, etc.) são qualidades cognitivas que regulam atividades intelectuais, vícios epistêmicos, ao contrário, dificultam o exercício de nossas capacidades intelectuais na busca da verdade (ZAGZEBSKI, 1996; HOOKWAY, 2003; BAEHR, 2011).

De acordo com a teoria obstrutivista de Quassim Cassam (CASSAM, 2019), há duas condições necessárias para caracterizar vícios epistêmicos: a primeira trata de seus efeitos sobre o conhecimento, enquanto a segunda, da responsabilidade dos agentes. Assim, um hábito de conduta é um vício epistêmico se: (i) ele for sistematicamente prejudicial ao conhecimento, ou seja, se ele obstrui o conhecimento em quaisquer de suas etapas, seja na aquisição, na manutenção, na elaboração ou na transmissão de informações; e (ii) se os agentes (ou a comunidade)

\footnotetext{
1 Ou ainda, sequer o considerasse como fonte de informação, o que seria uma consequência da injustiça testemunhal: o"silenciamento" de determinados grupos sociais (FRICKER, 2007, p. 130). Apesar dos exemplos e casos discutidos neste artigo se referirem a indivíduos (agentes ou sujeitos epistêmicos), as injustiças epistêmicas também incidem sobre comunidades cujas "vozes" não são reconhecidas como produtoras de conhecimento.
} 
puderem ser culpabilizáveis por esses maus efeitos, seja pela aquisição desses vícios ou pela falta de correção deles.

Injustiças epistêmicas certamente atendem à primeira condição, que podemos chamar de consequencialista, isto é, que trata das consequências dos vícios epistêmicos. E podem atender à segunda, responsabilista, considerando-se que, no caso de preconceitos implícitos, sobre os quais o indivíduo não tem nenhum controle, seja adotada uma concepção não-voluntarista de responsabilidade (SHER, 2006). Deste modo, mesmo em casos nos quais o agente não possa ser responsável, seja pela aquisição ou correção de seus vícios epistêmicos, ele ainda assim pode, de algum modo, ser culpável ou censurável por eles. A despeito de considerável parcela do debate atual sobre o assunto aconteça em torno desta segunda condição (KIDD, 2016; BATTALY, 2017; 2019), a problemática deste trabalho destaca a primeira, consequencialista, que trata da obstrução do conhecimento.

Sob esse aspecto, os efeitos prejudiciais dos vícios epistêmicos sobre a inquirição podem ocorrer dos seguintes modos, de acordo com diferentes etapas do processo (aquisição, elaboração, manutenção e transmissão):

(i) Aquisição: vícios epistêmicos reduzem as chances de um agente atingir uma crença verdadeira e não falsa. Uma pessoa dogmática, por exemplo, teria mais chances de crer falsamente que "A Terra é plana", por não ser sensível a vastas evidências contrárias.

(ii) Elaboração²: diminuem a confiabilidade das bases justificatórias de uma crença. Por exemplo, um cientista arrogante ignora evidências contrárias à sua teoria e se apoia apenas naquelas que corroboram suas hipóteses.

(iii) Manutenção: dificultam a manutenção de uma crença verdadeira, seja por falta de confiança ou coragem epistêmica de sustentá-las em ambientes que lhe são hostis.

(iv) Transmissão: pelos mesmos motivos anteriores, vícios epistêmicos prejudicam o compartilhamento de crenças verdadeiras e, assim, globalmente, afetam toda a comunidade de inquiridores.

Nos efeitos descritos acima, as etapas de (i) a (iii) são mencionadas em Cassam (2019, p. 11), e o último tipo de efeito, a etapa (iv), afirmamos que decorrem das demais. Os efeitos prejudiciais listados em (iii) e (iv), em particular, serão explorados adiante.

No conhecimento testemunhal, há, de forma mais evidente, efeitos que incidem sobre a obtenção de conhecimento por parte do ouvinte (i), e de transmissão por parte do falante (iv). Fricker reconhece esses dois pontos listados como compostos de um aspecto mais evidente do prejuízo causado por injustiça epistêmica testemunhal: "Há, obviamente, um dado puramente epistêmico que ocorre quando estereótipos preconceituosos distorcem juízos de credibilidade: o conhecimento que seria passado para um ouvinte não é recebido" (FRICKER, 2007, p. 43). Esse tipo de consequência, porém, não se restringe à transmissão do conhecimento, mas repercute em todo o processo, "[...] pois o preconceito representa um obstáculo à verdade, seja diretamente, levando o ouvinte a falhar em obter uma verdade em particular, ou indiretamente, obstruindo a circulação de ideia críticas" (FRICKER, 2007).

A resposta à questão se a injustiça epistêmica é um vício epistêmico, portanto, considerando-se apenas a condição de prejuízo, é afirmativa. Entretanto, injustiças epistêmicas, em

\footnotetext{
2 Elaboração, aqui, quer dizer processamento de informações, justificação, correção e revisão de crenças.
} 
particular a testemunhal, são uma espécie de vício epistêmico cujos efeitos são mais amplos do que até aqui pode-se cotejar.

A epistemologia dos vícios e virtudes epistêmicas de Cassam (2019), Baehr (2011) e Hookway (1994), entre outros, tem um eixo teórico (a meu ver correto) na inquirição, seja ela científica ou não. Conforme diz Hookway, "[...] o foco de nossas 'vidas epistêmicas' é a atividade de inquirição", quer dizer, "nossa tentativa de descobrir a verdade", para ampliar ou refinar o conhecimento (HOOKWAY, 1994, p. 211).

Mas essa escolha teórica e metodológica tem um limite. Ela não permite compreender um espectro mais amplo de prejuízos causado pelas injustiças epistêmicas, e nem classificar essas injustiças testemunhais como um tipo mais específico de vício epistêmico. Para isso, o foco precisa ser, ao mesmo tempo, especificado e ampliado. Primeiro, especificado, observando que a relação epistêmica testemunhal entre agentes não é simétrica. É preciso, diz Fricker, analisar esses danos causados ao falante. Aqui, o principal prejuízo, diz a filósofa, é excluir o falante da comunidade de conhecimento, em razão de preconceito identitário. Em segundo lugar, ampliado, observando que os prejuízos podem ser mais extensos e duradouros sobre esses indivíduos.

Fricker divide esses tipos de efeitos sobre um dos polos da interlocução (o falante) em dois tipos, primários e secundários.

O aspecto primário é o falante ser injustiçado em sua capacidade epistêmica de transmitir conhecimento (item [iv] listado acima). Isso, contudo, provoca efeitos mais profundos do que um mero impedimento de transmissão da mensagem. Trata-se de negar um traço considerado essencial ao valor humano: sua racionalidade ${ }^{3}$.

Ser injustiçado em sua capacidade como conhecedor é ser injustiçado em uma capacidade essencial ao valor humano. Quando alguém é prejudicado ou, de outra forma, injustiçado em uma capacidade essencial ao valor humano, ele sofre uma injustiça intrínseca (FRICKER, 2007, p. 44).

O que se está negando ao agente, portanto, não é somente o exercício de práticas epistêmicas regulares na comunidade, mas também sua própria humanidade.

Segundo Fricker a credibilidade possui dois elementos distintos: competência e sinceridade (2007, p. 45). Casos de injustiça epistêmica, neste nível primário, pode incidir sobre ambos os elementos, ou apenas sobre um deles. Uma mulher que sofre preconceito de gênero, por exemplo, pode ser vítima de injustiça epistêmica que afeta o componente de sinceridade, quando sua fala é descreditada em uma denúncia de assédio sexual. Ou pode também ter sua competência questionada, no caso de ser depreciada como autoridade científica. Em ambos esses exemplos hipotéticos, diz Fricker: “Uma vez que credibilidade epistêmica requer a conjunção de competência e sinceridade, um ataque injusto sobre um ou outro componente é suficiente para ser injustiçado nessa capacidade" (FRICKER, 2007, p. 45).

O aspecto secundário, por sua vez, divide-se em uma dimensão prática e outra teórica. A dimensão prática, segundo a autora, refere-se a consequências práticas, pontuais ou duradoras, causadas por injustiças testemunhais. Um negro pode ser condenado injustamente por um júri branco (pontual), ou uma mulher pode sentir-se incapaz para realizar tarefas intelectuais por preconceito de gênero, acomodando-se a atividades domésticas (duradoura).

Já o aspecto teórico resulta em uma perda gradual e contínua da confiança do indivíduo enquanto agente epistêmico, em sua própria capacidade de justificar e manter crenças verda-

\footnotetext{
${ }^{3}$ Por racionalidade podemos entender aqui, no espírito da autora, não somente a capacidade de praticar determinadas faculdades cognitivas, como o uso da linguagem, mas também em termos de uma racionalidade prática, conforme discutimos a seguir a respeito do conceito de segunda natureza.
} 
deiras (item [iii] descrito acima). Porém, isso não deve ser visto como apenas uma diminuição de sua qualidade enquanto agente epistêmico, mas - este é o ponto da autora - enquanto ser humano. "Uma pessoa com um repertório de experiência com injustiça epistêmica testemunhal persistente pode perder a confiança em suas habilidades intelectuais em geral, de tal forma que isso realmente dificulta seu desenvolvimento educacional e intelectual" (FRICKER, 2007, p. 47-48).

Isso ocorre em razão da falta de confiança afetar a manutenção e a justificação de crenças verdadeiras, ou, de modo menos direto, de desenvolver virtudes relevantes para a vida intelectual, como coragem (FRICKER, 2007, p. 49). É o caso, por exemplo, de um estudante pobre que não dá continuidade aos seus estudos por ser desacreditado por seus professores, devido a preconceito. Juntos, efeitos primários e secundários relevam um quadro opressivo:

A implicação da injustiça testemunhal persistente é que a performance intelectual do sujeito pode, a longo prazo, ser inibida, sua confiança abalada e desenvolvimento, frustrado [...]. Colocando o prejuízo primário juntamente com os extensivos prejuízos secundários que podem ser causados, temos agora um retrato de uma injustiça que mostra ser capaz de operar profunda e amplamente na psicologia da pessoa e na vida prática. Onde não é somente persistente, mas também sistemática, a injustiça testemunhal apresenta uma face de opressão. (FRICKER, 2007, p. 58).

Os efeitos repercutem assim na formação do próprio self, da identidade pessoal e social (FRICKER, 2007, p. 53-55), gerando exclusão e marginalização de grupos e "silenciamento" e objetificação de indivíduos (FRICKER, p. 130-133). Em última instância, gera uma desumanização. Esta parece, portanto, ser uma dimensão inteiramente nova em relação a outros vícios epistêmicos.

Uma maneira de entender melhor a extensão desses prejuízos epistêmicos causados por injustiça testemunhal é por meio do conceito de segunda natureza, de McDowell (1998). Quando um falante é vítima de injustiça testemunhal, lhe é negado o direito de adentrar aquilo que Sellars chamou de "espaço lógico das razões" (SELLARS, 2008). Esse conceito caracteriza uma esfera pública na qual agentes epistêmicos exercem suas capacidades racionais e cognitivas, como o uso da linguagem e argumentação lógica. Mas, de acordo com McDowell, esse espaço não é somente teórico e lógico, mas ético, de formação de caráter e virtudes, de exercício daquilo que Aristóteles chamou de sabedoria prática (phronesis).

Moldar o caráter ético - o que inclui a imposição de uma forma específica ao intelecto prático - é um caso particular de um fenômeno mais geral: a iniciação nas nossas capacidades conceituais, que inclui responsividade a outras exigências racionais, além das exigências éticas. Essa iniciação normalmente faz parte daquilo que está envolvido no amadurecimento de um ser humano [...]. Se generalizarmos o modo como Aristóteles concebe a modelagem do caráter ético, chegaremos à noção de possuir olhos abertos às razões em geral por meio da aquisição de uma segunda natureza. Não me ocorre nenhuma expressão curta da língua inglesa para traduzir esta ideia, mas é a que está envolvida no sentido da palavra alemã Bildung (McDOWELL, 1998, p. 122). ${ }^{4}$

Quando uma pessoa sofre injustiça epistêmica, na extensão discutida em Fricker, ela não é somente impedida de expressar conhecimento, significado, mas de exercitar potencialidades naturais, incluindo essas de segunda natureza. Ou seja, ela é impedida de se desenvolver como ser humano, de alcançar sua maturidade intelectual e ética. São esses traços que tentaremos exemplificar na obra de Lima Barreto, de forma a contribuir para o debate sobre vícios epistêmicos.

\footnotetext{
${ }^{4}$ O conceito Building, na concepção gadameriana, e sua relação com a ideia de segunda natureza, em McDowell, são analisados no artigo de RICHTER, 2019.
} 


\section{Injustiça testemunhal em Recordações do escrivão Isaías Caminha}

Afonso Henriques de Lima Barreto (1881-1922) é um dos mais importantes escritores pré-modernistas brasileiros, mais conhecido pela obra O Triste Fim de Policarpo Quaresma (1915). Nos últimos anos, estudos têm explorados aspectos da crítica social do autor, sua afrodescendência e suas denúncias do racismo que estruturou as divisões de classe no país (SCHWARCZ, 2017). Lima Barreto viveu no período da Primeira República (1881-1930), cuja Abolição da Escravatura (1888) não se traduziu em melhoria das condições de vida da população negra no país. Pelo contrário, a situação da população afrodescendente no país, abandonada à própria sorte pela elite escravocrata, tornou-se ainda mais precária. Os negros não somente não conseguiram inserir-se no mercado de trabalho como tiveram que competir, em condições desiguais, com a mão-de-obra branca dos imigrantes europeus (FERNANDES, 2008; CARVALHO, 2019; AZEVEDO, 1987).

A obra de Lima, composta por romances, contos, crônicas e diários, reflete essas tensões sociais e raciais da sociedade brasileira do início de século, com críticas feitas em um estilo direto e incisivo.

Uma outra marca característica da obra de Lima Barreto é seu caráter autobiográfico, presente nos personagens e nas situações descritas em seus romances, alguns dele escritos em estilo à clef. Seu livro de estreia na literatura, Recordações do escrivão Isaías Caminha (1909), é talvez o exemplo mais bem realizado disso. Nesse romance, acompanhamos a trajetória do personagem que dá título à obra, um jovem inteligente e educado, de sua saída do interior em direção à capital, Rio de Janeiro, com a intenção de formar-se "doutor". No decorrer dos anos, sofre com o preconceito racial e, aos poucos, abandona seus projetos e acomoda-se a um cotidiano apático. A obra traz diversos elementos biográficos do autor, de origem humilde e neto de escravos, que abandonou a faculdade de engenharia civil para trabalhar na imprensa e, a muito custo, publicar seus romances (BARBOSA, 2017; SCHWARCZ, 2017).

Isaías Caminha retrata uma sociedade brasileira que, ao mesmo tempo em que se moderniza nos espaços urbanos e na política, com as expectativas trazidas pela República e o fim da escravidão, mantém as estruturas racistas e hegemônica das elites oligárquicas. É neste contexto histórico que podemos observar, na ficção, os efeitos deletérios de injustiças testemunhais gerados por preconceito racial, conforme descritos na seção anterior. Além dos traços biográficos, a escrita em primeira pessoa reforça o tipo de experiência que pretendemos observar e analisar. Como afirma Bosi, acerca desse romance, "[...] a ficção em primeira pessoa abre as portas do sujeito e sonda os efeitos devastadores de um gesto talvez automático de preconceito" (BOSI, 2010, p. 17).

Além disso, o relato, em tom memorialista, evidencia os mecanismos de ascensão social por meio da educação, que tornaria "aceitável" a condição racial do protagonista. É assim que, ao lembrar seus sonhos de juventude, já cônscio de suas origens afrodescendentes, diz: "Ah! Seria doutor! Resgataria o pecado original de meu nascimento humilde, amaciaria o suplício premente, cruciante e onímodo de minha cor...!" (BARRETO, 2010, p. 75). Isso condiz com o que Almeida (2020) relata - ainda que no contexto das modernas sociedades de consumo - sobre os processos históricos e políticos envolvidos no racismo estrutural. ${ }^{5} \mathrm{O}$ filósofo afirma que, no Brasil, diferentemente dos Estados Unidos, são levados em conta nos modos de classificação racial:

\footnotetext{
${ }^{5}$ Racismo é estrutural quando ele "[...] é uma decorrência da própria estrutura social, ou seja, do modo'normal' com que se constituem as relações políticas, econômicas, jurídicas e até familiares [...]" (ALMEIDA, 2020, p. 50).
} 
[...] além da aparência física de descendência africana, o pertencimento de classe explicitado na capacidade de consumo e na circulação social. Assim, a possibilidade de"transitar"em direção a uma estética relacionada à branquitude, e manter hábitos de consumo característicos da classe média, pode tornar alguém racialmente “branco" (ALMEIDA, 2020, p. 56).

Poderíamos acrescentar que mecanismos similares garantiriam a grupos segregados o acesso ao "espaço lógico das razões", no qual Isaías Caminha seria reconhecido como um agente epistêmico confiável, não marginalizado. Conforme o narrador diz na sequência: "Não titubearia, não hesitaria, livremente poderia falar, dizer bem alto os pensamentos que se estorciam no meu cérebro" (BARRETO, 2010, p. 75). Esse relato revela como as mesmas estruturas sociais racializadas estavam não somente presentes no contexto da Primeira República, mas que nele se firmaram, alicerçadas por teorias raciais científicas da Europa do século 19 e práticas socioculturais de branqueamento da população (SCHWARCZ, 1993; ALBUQUERQUE, 2009).

O objetivo deste artigo não é fazer uma análise de todas as situações de racismo descritas no livro, mas evidenciar os efeitos de injustiças testemunhais em algumas dessas passagens. Por isso, nos ateremos aos cenários que podem ser interpretados com base no quadro teórico exposto na seção anterior, seguindo a ordem que aparecem no romance.

O primeiro confronto com um termo pejorativo usado com frequência para descrever um homem negro na obra, "mulatinho", acontece na delegacia de polícia. Isaías Caminha é intimado a prestar depoimentos sobre um furto ocorrido no hotel no qual se hospeda. Tem-se então o seguinte diálogo com o delegado:

- Qual é a sua profissão?

- Estudante.

- Estudante?!

- Sim, senhor, estudante - repeti com firmeza.

- Qual estudante, qual nada! [...]

Com ar de escarninho, perguntou:

- Então, você é estudante? (BARRETO, 2010, p. 133).

A desconfiança do delegado de polícia ao fato de um negro alegar que ser estudante é um caso de injustiça testemunhal. Esse vício epistêmico incide, como efeito primário, sobre a sinceridade - e menos sobre a competência - do falante em seu testemunho. O personagem assim descreve tais efeitos:

Dessa vez tinha-o compreendido, cheio de ódio, cheio de um santo ódio que nunca mais vi chegar em mim. Era mais uma variante daquelas humilhações que eu já sofrera; era o sentimento geral da minha inferioridade, decretada a priori, que eu adivinhei na sua pergunta" (BARRETO, 2010). ${ }^{6}$

É interessante nesta passagem que Isaías se refere a "uma variante daquelas humilhações", pois injustiça testemunhal pode ser entendida como uma variante de injustiças sociais. E, ao dizer que é "decretada a priori", cremos que visa preconceitos implícitos ou estruturais, que associam determinadas características a um grupo marginalizado.

\footnotetext{
${ }^{6}$ Essa passagem em Isaías Caminha lembra um episódio da vida de Lima Barreto, relatado por Barbosa (2017), passado nos tempos da Politécnica. Na época, os colegas do curso de engenharia, todos brancos de classe média alta, combinaram pular os muros do teatro para assistir a um espetáculo. Barreto se recusou a participar da pilhéria, alegando que poderia ser preso como ladrão de galinhas. "Ah! Vocês, brancos, eram 'rapazes da Politécnica' [...]. Mas eu? Pobre de mim. Um pretinho. Era seguro logo pela polícia. Seria o único a ser preso." (BARBOSA, 2017, p. 106; SCHWARCZ, 2017, p. 122).
} 
Esse efeito primário que atinge a confiança do falante é acompanhado de efeito secundário e prático na vida do narrador: o ato de revolta que o leva a ser preso, por algumas horas, na cadeia. Mas, tornando-se sistemáticas, essas práticas de injustiças testemunhais vão, aos poucos, inibindo seus anseios de estudar, de ser aceito na sociedade e de amadurecer intelectualmente. Logo, temos indícios de efeitos primários que inibem a realização de capacidades cognitivas de segunda natureza e secundários mais amplos, que impedem o desenvolvimento dessa mesma racionalidade prática. Notam-se consequências tanto epistêmicas quanto afetivas. As ambições do narrador são, gradativamente, dando lugar ao amargor, a tristeza e a perda de confiança em si mesmo. O seguinte trecho mostra o começo desse declínio:

O que me fazia combalido, o que me desanimava eram as malhas de desdém, de escárnio, de condenação em que me sentia preso. Na viagem, vira-as manifestar-se ${ }^{7}$; no Lage da Silva $^{8}$, na delegacia, na atitude do delegado, numa frase meio dita, num olhar, eu sentia que a gente que me cercava, me tinha numa conta inferior. Com que percebia que estava proibido de viver e fosse qual fosse o fim da minha vida os esforços haviam de ser titânicos (BARRETO, 2010, p. 141).

Um caso de efeito primário que afeta em específico a competência do falante pode ser observado na segunda parte do romance (a partir do capítulo VIII), que se passa na redação do jornal O Globo . Isaías havia então sido contratado como contínuo, apesar de ser muito qualificado para o cargo. É um caso também interessante, pois ainda que não atinja o protagonista diretamente, tem efeitos indiretos sobre ele. O diálogo se dá entre Isaías e o crítico do jornal, Floc $^{10}$, que recebe o livro de um jovem poeta iniciante:

Depois de manuseá-lo um instante, falou [Floc] com azedume:

- Que nome! Félix da Costa! Parece até enjeitado! É um mulatinho?

- Não. É mais branco que o senhor. É louro e tem olhos azuis.

- Homem, você hoje está zangado...

Ele também não compreendia que eu também sentisse e sofresse. (BARRETO, 2010, p. 257). ${ }^{11}$

É nessa mesma redação de jornal onde, mais uma vez, sofrendo constantes ataques de injustiças testemunhal e diante da recusa em o aceitarem como agente epistêmico qualificado que, aos poucos, os efeitos secundários práticos se aprofundam. Como nesse seguinte trecho no qual, já passados dois anos no Rio de Janeiro, o narrador, ao se queixar do comportamento racista dos colegas, lembra o distanciamento da mãe, negra, que morrera há dois meses:

\footnotetext{
7 O primeiro confronto do personagem com uma conduta racista ocorre quando, a caminho do Rio, ao tomar um café em uma estação rodoviária, o balconista se mostra indignado quando Isaías Ihe cobra o troco. "Ao mesmo tempo ao meu lado, um rapazola alourado reclamava o [troco] dele, que lhe foi prazenteiramente entregue" (Ibidem, p. 80). Isaías revolta-se diante do tratamento desigual e, somente mais tarde, adquire uma consciência de sua negritude como causa de tal afronta.

${ }^{8}$ Lages Silva é o personagem caricaturado de Paschoal Segreto (1868-1920), empresário de jogos de azar, preso várias vezes (BARRETO, 2010, p. 85). Aqui a referência é à demonstração de espanto desse personagem ao Isaías dizer que era estudante, em uma passagem mais implícita de injustiça testemunhal.

${ }^{9}$ O Globo, no romance, é um nome inventado por Barreto para retratar o Correio da Manhã, jornal carioca (1901-1974) no qual trabalhou.

${ }^{10} \mathrm{O}$ crítico literário Frederico Lourenço Couto, o Floc, é João Itiberê da Cunha (1870-1953), um dos fundadores do Correio da Manhã (BARRETO, 2010, p. 181).

${ }^{11}$ Não sendo reconhecido como sujeito do conhecimento, o negro, no romance, é objeto do conhecimento, conforme as teorias antropológicas que davam suporte ao racismo científico, muito em voga à época (SCHWARCZ, 1993). Esse contexto é retratado no capítulo $X$, quando um médico legista examina o cadáver masculino de um casal vítima de homicídio para concluir, erroneamente, que era negro, sugerindo crime motivado por relação inter-racial ("amor proibido") (BARRETO, 2010, p. 236-238).
} 
Os ditos de Floc, as pilhérias de Losque ${ }^{12}$, as sentenças do sábio Oliveira ${ }^{13}$, tinham feito chegar a mim uma espécie de vergonha pelo meu nascimento, e esse vexame me veio diminuir em muito a amizade e ternura com que sempre envolvi a sua [mãe] lembrança. Sentia-me separado dela. Conquanto não concordasse em ser ela a espécie de besta de carga e máquina de prazer que as sentenças daqueles idiotas a abrangiam no seu pensamento de lorpas, entretanto eu, seu filho, julgava-se a meus próprios olhos muito diverso dela, saído de outra estirpe, de outro sangue e de outra carne. (BARRETO, 2010, p. 262).

Esses efeitos duradouros das injustiças testemunhais (e, de modo, geral, do racismo estrutural vigente) é ambivalente no personagem. Por um lado, ele toma das injustiças contra todos de sua condição social e racial, a qual não é permitido expressarem-se como agentes epistêmicos confiáveis. Por outro, provoca no autor um sentimento de afastamento de sua própria origem, representada pela sua mãe, à medida que ainda persegue os sonhos de ser "doutor", de ser aceito no espaço de razões mediante branqueamento social. Essa tensão reflete aquela vivida pelo próprio escritor, Lima Barreto, que vivia nos subúrbios cariocas, juntamente com famílias pobres e, ao mesmo tempo, sentia-se delas apartado por suas propensões intelectuais. A passagem continua:

Ainda não tinha coordenado todos os elementos que mais tarde vieram encher-me de profundo desgosto e a minha inteligência e a minha sensibilidade não tinham organizado bem e disposto convenientemente o grande stock de observações e de emoções que eu vinha fazendo e sentido dia a dia. Vinham uma a uma, invadindo-me a personalidade insidiosamente para saturar-me mais tarde até o aborrecimento e ao desgosto de viver. (BARRETO, 2010, p. 262-263).

Novamente o narrador se refere a habilidades intelectuais e afetivas, o que mostra que o espaço de razões é um também um espaço do florescimento de motivações e virtudes epistêmicas. Assim, aliado a efeitos secundários de dimensão prática, podem ser observados efeitos secundários de dimensão teórica, na continuação do mesmo trecho citado:

\footnotetext{
Houve mesmo um dia em que quis avaliar ainda o que sabia. Tentei repetir a lista dos Césares - não sabia; quis resolver um problema de regra de três composta, não sabia; tentei escrever a fórmula da área da esfera, não sabia. E notei essa ruína dos meus primeiros estudos cheio de indiferença, sem desgosto, lembrando-me daquilo tudo como impressões de uma festa a que fora e a que não devia voltar mais. Nada me afastava da delícia de almoçar e jantar por sessenta mil-réis mensais (BARRETO, 2010, p. 263).
}

Ao fim do romance, os efeitos primários e secundários de injustiças testemunhais resultam, desse modo, em uma perda gradual de conhecimento e de virtudes intelectuais. Em suma, na perda de uma parcela importante do próprio self de um Isaías Caminha, agora adulto, impedido de cumprir suas aspirações, desejos e realizações de potencialidades de sua infância. Essa obstrução do pleno exercício de suas capacidades de segunda natureza ("[...] uma festa a que fora e a que não devia voltar mais") - efeito primário -, causa-Ihe, ao fim, indiferença ante a recusa do amadurecimento intelectual e entrega a uma vida mundana ("Nada me afastava da delícia de almoçar e jantar por sessenta mil-réis mensais") (efeito secundário teórico). Tem-se, por um lado, danos ao indivíduo impedido de exercer sua capacidade de produzir, difundir e elaborar conhecimento, e por outro, de lhe ser obstado o refinamento ético e intelectual, sua sabedoria prática. A literatura de Lima Barreto é pungente em descrever esse processo que leva, em última instância, a estados de objetificação e desumanização:

\footnotetext{
12 O jornalista e humorista Gastão Bousquet (1870-1917), redator-chefe do Correio da Manhã (BARRETO, 2010, p. 184).

${ }^{13}$ Outro jornalista, personagem fictício.
} 
[...] no fim estava sombrio, calado e cheio de remorsos. Desesperava-me o mau emprego dos meus dias, minha passividade, o abandono das grandes ideias que alimentara (BARRETO, p. 296). [...] Que tinha feito? Que emprego dera à minha inteligência e à minha atividade? Essas perguntas angustiavam-me. (BARRETO, 2010, p. 299).

\section{Conclusões}

Injustiça epistêmica é um tipo mais específico de vício epistêmico, que afeta particularmente o conhecimento testemunhal - aquele que resulta da interlocução de agentes e baseia-se, primariamente, em contratos de confiança. Mas, ao mesmo tempo, tem efeitos muito mais amplos sobre indivíduos e grupos, servindo, assim, como um importante conceito teórico para se examinar formas de opressão sobre comunidades marginalizadas por preconceitos sociais, raciais e de gênero.

Neste artigo mostramos que a exclusão de grupos marginalizados, apartados do espaço de produção e compartilhamento do conhecimento, provoca efeitos duradouros que afetam a própria constituição do ser humano, pois o impossibilita de exercer e desenvolver suas capacidades cognitivas e éticas, sua segunda natureza. Isso afeta toda uma comunidade, não somente porque os efeitos dificultam a transmissão e aquisição de conhecimento por agentes capacitados, mas porque, em sociedades democráticas, gera exclusão política e social.

Tais conclusões resultaram da análise da obra inaugural de Lima Barreto, Recordações do escrivão Isaías Caminha (1909), ele próprio um escritor negro, ativista e crítico social, cuja vida, assim como o protagonista do romance, foi aluída pelo racismo em vigor à época. Observamos, na narrativa, casos que puderam ser caracterizados como efeitos primários e secundários de injustiças testemunhais, conforme definidos por Fricker, em reflexões que ampliam a perspectiva teórica da autora. Por esta razão, cremos que pesquisas futuras que explorem essa proposta interpretativa da obra de Lima Barreto, em especial em seus contos e romances, poderão revelar mais sobre os aspectos filosóficos desse escritor brasileiro, bem como estreitar as relações interdisciplinares entre a literatura brasileira e a epistemologia contemporânea.

\section{Referências}

ALMEIDA, Silvio Luiz de. Racismo estrutural. $3^{a}$ reimpressão. São Paulo: Sueli Carneiro; Pólen, 2020. (Col. Feminismos Plurais).

ALBUQUERQUE, Wlamyra R. de. O jogo da dissimulação: abolição e cidadania negra no Brasil. São Paulo: Companhia das Letras, 2009.

AZEVEDO, Celia Maria Marinho de. Onda negra, medo branco: o negro no imaginário das elites - século XIX. Rio de Janeiro: Paz e Terra, 1987.

BAEHR, Jason. The inquiring mind: On intellectual virtues and virtue epistemology. Oxford: Oxford University Press, 2011.

BARBOSA, Francisco de Assis. A vida de Lima Barreto. 11. ed. Belo Horizonte: Editora Autêntica, 2017. BARRETO, Lima. Diário íntimo: memórias. 2. ed. São Paulo: Brasiliense, 1961.

BARRETO, Lima. Recordações do escrivão Isaías Caminha. Introdução de Alfredo Bosi; prefácio de Francisco de Assis Barbosa; notas de Isabel Lustosa. 2. ed. São Paulo: Penguin Classics Companhia das Letras, 2010. 
BATTALY, Heather. Testimonial injustice, epistemic vice, and vice epistemology. In: KIDD, lan James; MEDINA, José; and POHLHAUS Jr, Gaile (Eds.). The Routledge Handbook to Epistemic Injustice. New York: Routledge, 2017. p. 507-525.

BATTALY, Heather. Vice epistemology has a responsibility problem. Philosophical Issues, v. 29, n.1, p. 24-36, Oct. 2019.

BOSI, Alfredo. Introdução: Figuras do eu nas recordações de Isaías Caminha. In: BARRETO, Lima. Recordações do escrivão Isaías Caminha. Introdução de Alfredo Bosi; prefácio de Francisco de Assis Barbosa; notas de Isabel Lustosa. 2. ed. São Paulo: Penguin Classics Companhia das Letras, 2010.

CARVALHO, José Murilo de. Os bestializados: o Rio de Janeiro e a República que não foi. 4. ed. São Paulo: Companhia das Letras, 2019.

CASSAM, Quassim. Vices of the mind: from intellectual to the political. Oxford: Oxford University Press, 2019.

FERNANDES, Florestan. A integração do negro na sociedade de classes. v. 1. 5. ed. São Paulo: Globo, 2008.

FRICKER, Miranda. Epistemic injustice: power \& the ethics of knowing. Oxford: Oxford University Press, 2007.

HADDOCK, A.; MILLAR A.; PRITCHARD, D. (Eds.). Social Epistemology. Oxford: Oxford University Press, 2010.

HOOKWAY, Christopher. Cognitive virtues and epistemic evaluations. International Journal of Philosophical Studies, v. 2, n. 2, p. 211-227, 1994.

HOOKWAY, Christopher. How to be a virtue epistemologist. In: DePAUL, Michael; ZAGZEBSKI, Linda (Eds.). Intellectual virtue: Perspectives from ethics and epistemology. Oxford/New York: Oxford University Press, 2003. p. 149-60.

KIDD, Ian James. Fault and non-fault responsibility for implicit prejudice: a space for epistemic "agent-regret". In: BRADY, Michael S.; FRICKER, Miranda. The epistemic life of groups. Essays in the Epistemology of Colletives. Oxford: Oxford University Press, 2016. p. 33-50.

McDOWELL, John. Mente e mundo. Tradução de João Vergílio Gallerani Cuter. Aparecida: Ideias \& Letras, 2005.

RICHTER, Bruna Natália. Bildung e segunda natureza: McDowell leitor de Gadamer. Griot: Revista de Filosofia. Amargosa, v.19, n.1, p.186-196, fevereiro, 2019.

SCHWARCZ, Lilia Moritz. O espetáculo das raças: cientistas, instituições e questão racial no Brasil - 1870-1930. São Paulo: Companhia das Letras, 1993.

SCHWARCZ, Lilia Moritz. Lima Barreto: triste visionário. São Paulo: Companhia das Letras, 2017.

SELLARS, W. Empirismo e filosofia da mente. Tradução de Sofia Inês Albornoz Stein. Petrópolis: Vozes, 2008.

SHER, George. In praise of blame. Oxford: Oxford University Press, 2006.

ZAGZEBSKI, Linda T. Virtues of the mind: An inquiry into the nature of virtue and the ethical foundations of knowledge. Cambridge: Cambridge University Press. 1996. 


\section{Sobre o autor}

\section{José Renato Salatiel}

Doutor em Filosofia. Professor da Universidade Federal do Espírito Santo (UFES). Atua atualmente na área de Epistemologia.

Recebido em: 02/07/2020.

Aprovado em: 22/09/2020.
Received: 02/07/2020.

Approved: 22/09/2020. 